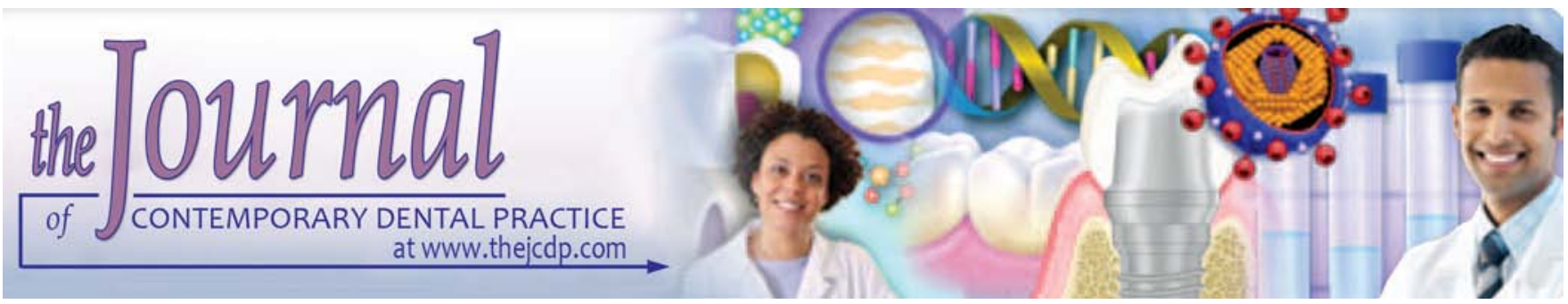

\title{
Interdental Implant Papillae Grow up with Temporary Abutment displaced at Monthly Intervals
}

\author{
Mohammed Jasim AL-Juboori
}

\begin{abstract}
Interdental papillae regeneration remains a challenge in implant dentistry in cases in which papillae are lost following tooth extraction. This report presents an implant case with missing 1st and 2nd premolars and total papillary loss. We performed immediate provisionalization to the first premolar implant with a temporary abutment and crown, whereas the second premolar was submerged. Crown contouring and modifications to the shape and size were performed once every month (the temporary abutment and crown disconnected three times during the 3-month healing period). At the end of the 3-month healing period, papillae regeneration was observed between the implant and the adjacent tooth and between the adjacent implants. Papillae regeneration is possible with temporary abutment and a composite material crown that is properly contoured and polished, even with several abutment removals during the healing period.
\end{abstract}

Keywords: Progressive implant loading, Interdental papillae, Gingival contour, Provisional crown, Emergence profile.

How to cite this article: AL-Juboori MJ. Interdental Implant Papillae Grow up with Temporary Abutment displaced at Monthly Intervals. J Contemp Dent Pract 2015;16(5):422-426.

\section{Source of support: Nil}

\section{Conflict of interest: None}

\section{INTRODUCTION}

Following tooth extraction, the interproximal papilla usually collapses due to the loss of tooth support. ${ }^{1}$

Gingival esthetics have become a crucial factor in the overall success of an implant-supported restoration. ${ }^{2}$

Department of Oral Surgery, MAHSA University, Kuala Lumpur Malaysia

Corresponding Author: Mohammed Jasim Al-Juboori Lecturer, Department of Oral Surgery, MAHSA University Dental Faculty, Block E, 4th Floor, Pusat Bandar Damansara Damansara Height, 50490, Kuala Lumpur, Malaysia, Phone: (+60) 0162417557, e-mail: doctor_mohamed_2006@yahoo. com
Peri-implant papillae regeneration is the most difficult and challenging aspect of dental implants. ${ }^{3}$ Some authors have reported the correction of the absence of a papilla by surgical techniques; however, regeneration of the papillae adjacent to dental implants remains complex and unpredictable., ${ }^{4,5}$

The papilla plays a protective role for the adjacent periodontium, including the alveolar bone crest, acting as a biological barrier against external aggressors and preventing food impaction. Moreover, its loss can lead to cosmetic deformities and phonetic problems. ${ }^{6}$

Patients highly value a harmonious gingival display in this zone of the mouth, and it contributes significantly to facial expression. ${ }^{7}$ An esthetic treatment outcome in single implant sites without tissue deficiencies is generally achieved, because it depends on the tissue support provided by the adjacent teeth. ${ }^{8}$ In contrast, achieving an esthetic outcome for multiple adjacent implants is a major challenge for the dental implant surgeon. ${ }^{9-11}$

Successful esthetic implant restoration should have an emergence profile that mimics the natural tooth. ${ }^{12}$ The emergence profile of the final restoration is affected by the shape, size and location of the implant platform. ${ }^{13}$

Some authors have followed up with patients whose implants were placed in the anterior position with an immediate provisional crown and with another group whose implants were placed the conventional way (twostage technique). There were no significant differences in the peri-implant mucosal response and the papilla index between the two groups over the course of 1 year. ${ }^{14}$

In another study, immediate provisionalization of the implant effectively optimized the peri-implant esthetic results. Because, the provisional crowns were placed in nonocclusal loading, the risk of complications was minimized. ${ }^{15}$

The change in the crown emergence profiles, together with the restored contact points, contributed to soft tissue conditioning and interdental papillae growth. ${ }^{16}$ 


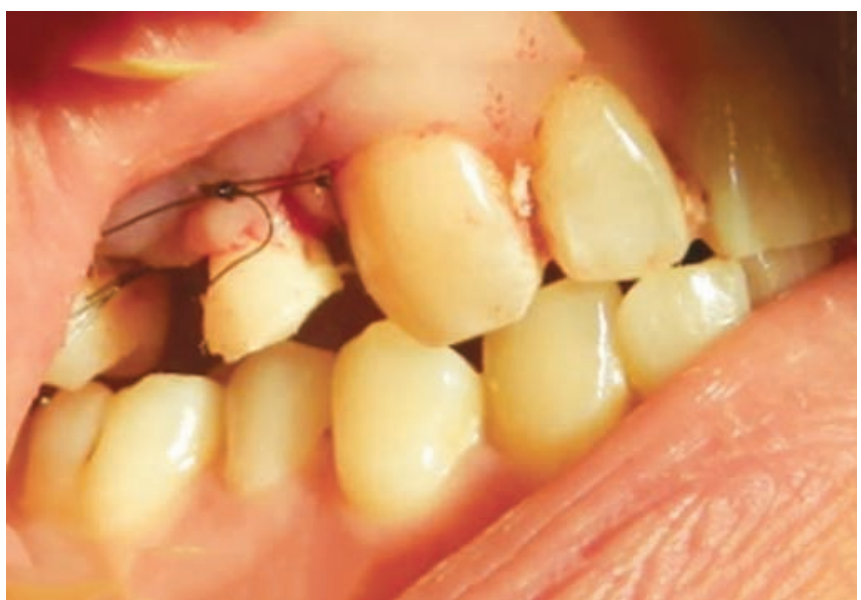

Fig. 1: Immediate temporary abutment and crown fabricated for the first premolar implant. Temporary crown is totally out of occlusion, with no contact with the adjacent tooth. The temporary crown is narrow at the neck, to let the gingival tissue growing. You can observe the papillae preserve incision in the distal of the canine

This case report describes how the gingival tissue and papillae grow around an immediately loaded implant with a temporary crown and abutment.

\section{CASE REPORT}

The patient was a 32-year-old woman with no history of any systemic disease or parafunctional occlusion. The patient presented at this facility to have her missing upper right 1st and 2nd premolar implants replaced. An orthopantomogram was performed after clinical and radiographic examination, and a $4.0 \mathrm{~mm}$ tapered implant, $10 \mathrm{~mm}$ in length (Superline, Dentium), was selected to replace both teeth. Under local anesthesia, a crestal incision was performed with 2 vertical extensions, and the interdental papillae were preserved. The bone was exposed and prepared according to the manufacturer's recommendation. The bone density was poor; therefore, the last drill was drilled halfway. For the 2nd premolar

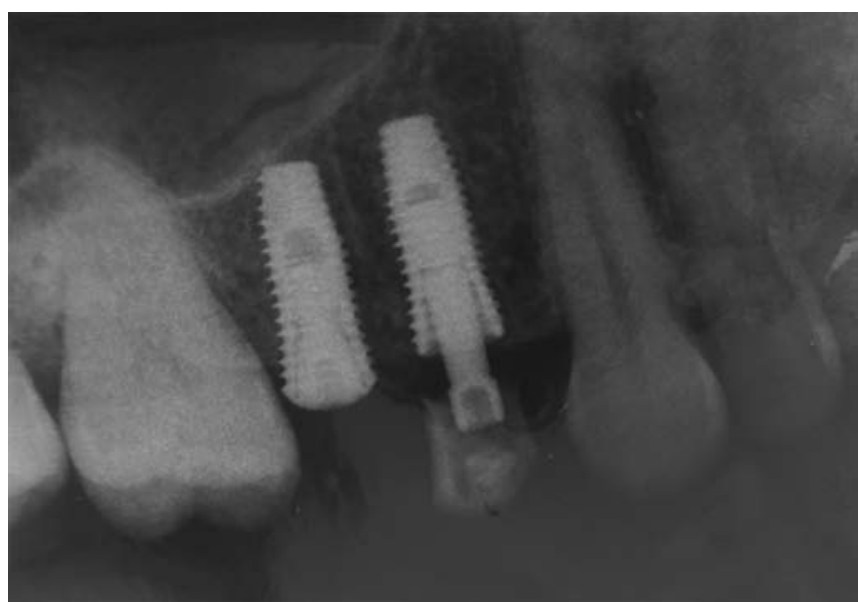

Fig. 2: Periapical radiograph immediately after implant placement. Fourteen implant immediately loaded with temporary abutment, while 15 implant left sleep implant

implant, a cover screw was placed, covered with gingival tissue, and primarily closed for healing by the submerged technique. The 1st premolar implant was immediately loaded with the temporary plastic abutment, and the crown was fabricated from a light-cured composite material (Fig. 1). At this stage, the crown lacked occlusion, with a narrow occlusal table, and had no adjacent contact (Fig. 1). The flap was adapted to the temporary crown, and gingival tissue was sutured around it (Fig. 1). A periapical radiograph was postoperatively conducted for both implants and was considered as a basic radiograph (Fig. 2). Postoperative instruction was provided; after 2 weeks, the patient returned for suture removal and review. Both implant sites healed uneventfully, and suture removal was performed. One month following implant placement, the temporary abutment and crown were unscrewed (Fig. 3), and the crown was modified by buccally and palatally increasing the width of the occlusal table, thereby making mesial contact with an adjacent tooth (upper right canine). The neck of the crown was still narrow, and the

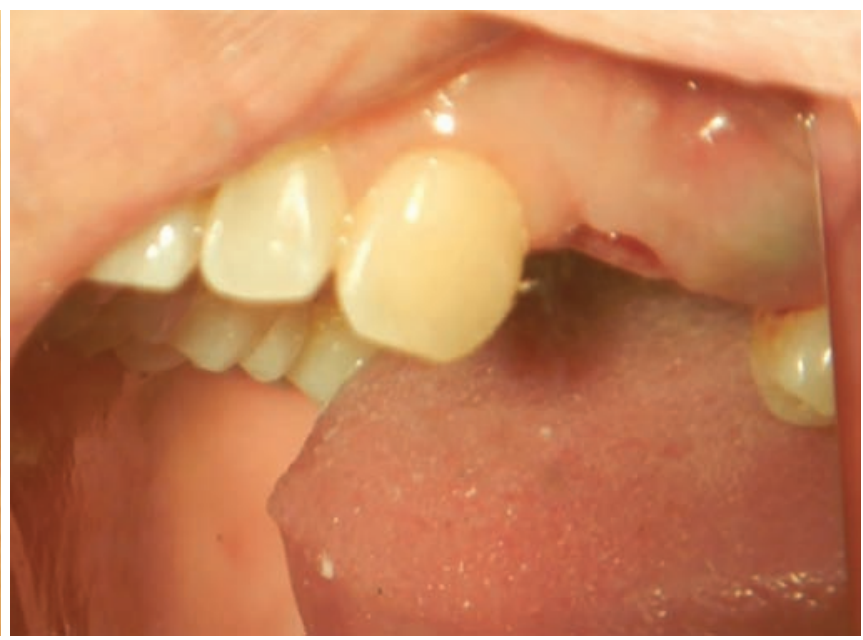

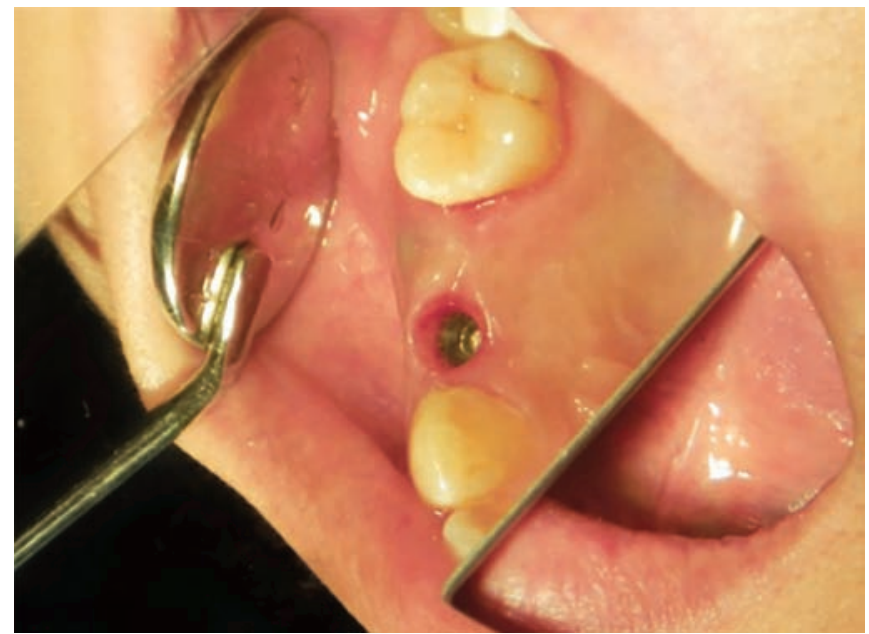

Fig. 3: After 1 month, the gingival tissue is mature around the temporary abutment and start to grow. Temporary abutment and crown was taking out at this stage for more modification in shape 


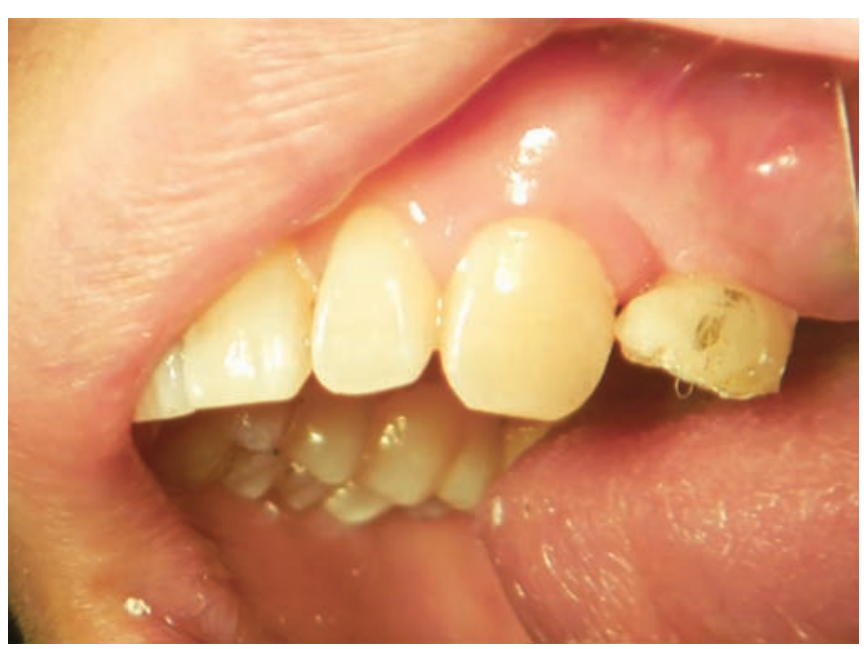

Fig. 4: After 1 month, the crown increases in width, with mesial contact with the distal of the canine

increase in the crown width was only above the gingival margin. At this stage, the crown was out of occlusion (no increase in the crown height). The crown was polished and again screwed into the fixture (Fig. 4). Two months after implant placement, the patient called again for the 3rd stage of crown modification. At this stage, the temporary abutment and crown were unscrewed, and we observed a greater increase in the height of the gingival collar and dental papillae. The crown was modified with anatomical contouring and shaping (Fig. 5). We increased the height of the crown and made occlusal contact with the agonist in only the axial direction. Occlusal contact in the excursion movement was removed, and only light central contact remained. The crown was polished and again screwed into the fixture. During the same appointment, the 2nd premolar implant was uncovered. A healing abutment was placed, which remained for 1 month to allow for soft tissue maturation. Four months after implant placement, the temporary abutment and

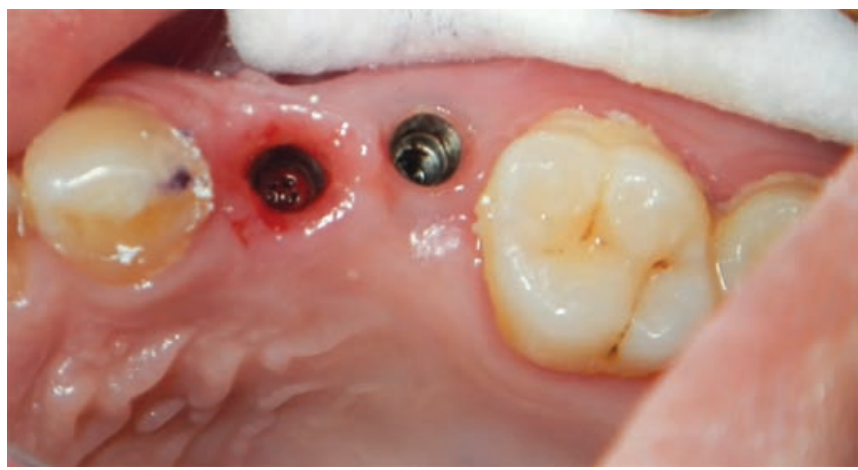

Fig. 6: After 4 months healing, we can observe the difference between the gingival collar that formed by the healing abutment at the 2nd premolar and gingival tissue formed from the temporary crown. We can observe the emergence gingival tissue that can adapt the crown to achieve the crown emergence profile and it is asymmetric anatomical profile of the gingival in the temporary crown

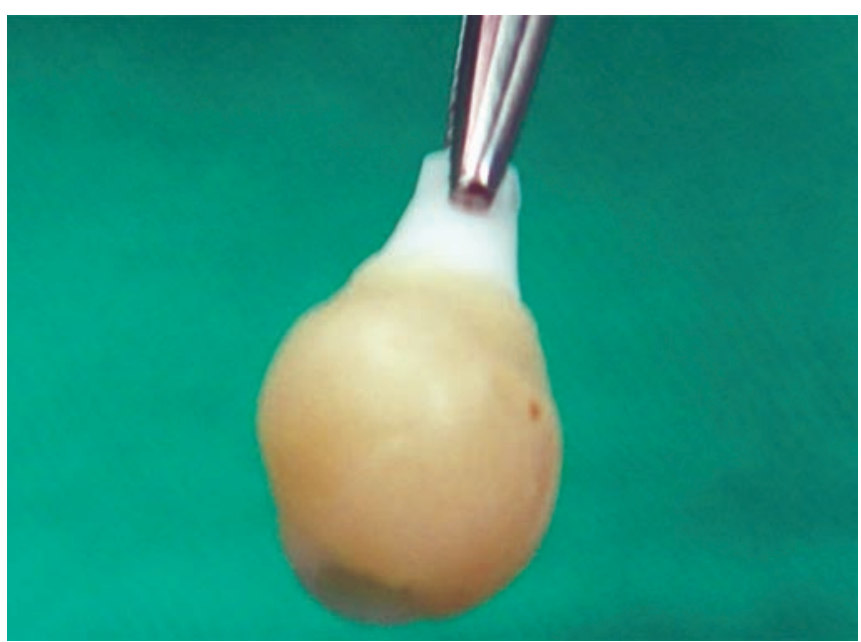

Fig. 5: After 2 months, the temporary crown and abutment dislodged and modified again to resemble more the tooth shape. The crown was increased in height to achieve light centric occlusion with agonist

healing abutment were unscrewed, and the emergence profiles of both implants were observed and compared. The emergence profile of the temporary crown and abutment was well formed, with a thick roll of gingival tissue that mimicked the emergence profile of the natural tooth (Fig. 6). At the same time, the gingival and dental papillae heights and growth of the two implants were evaluated and compared (Fig. 7). An impression was collected using the closed tray impression technique and hex impression coping. For both implants, a titanium hex abutment was screwed to $30 \mathrm{Ncm}$ (Fig. 8), and a provisional crown was cemented with temporary cementation. Occlusion was checked and adjusted; only centric occlusion was allowed, and all contact during excursion movement was removed (Fig. 9). A definite crown was issued 6 months after provisional crown placement.

\section{DISCUSSION}

Multiple adjacent implants in the esthetic zone can make it challenging for the surgeon to regenerate the missing papillae ${ }^{8}$. Many factors can influence papillae regeneration, and one important factor is the incision line. The incision line is important to preserve or regenerate the interdental papillae. ${ }^{17}$ The incision line includes the dental papillae and is reflected during the flap increase. There is a high chance of the dental papillae being lost or failing to regenerate during healing. ${ }^{18}$ The underlying cause of these issues is cutting of the periodontium that connects the papillae to the tooth, as this periodontium provides support for the dental papillae. The postulated minimum width of the interdental papilla $(1 \mathrm{~mm})$ to remain firmly attached to the adjacent tooth and bone assures that adequate blood supply will reach the papillary 

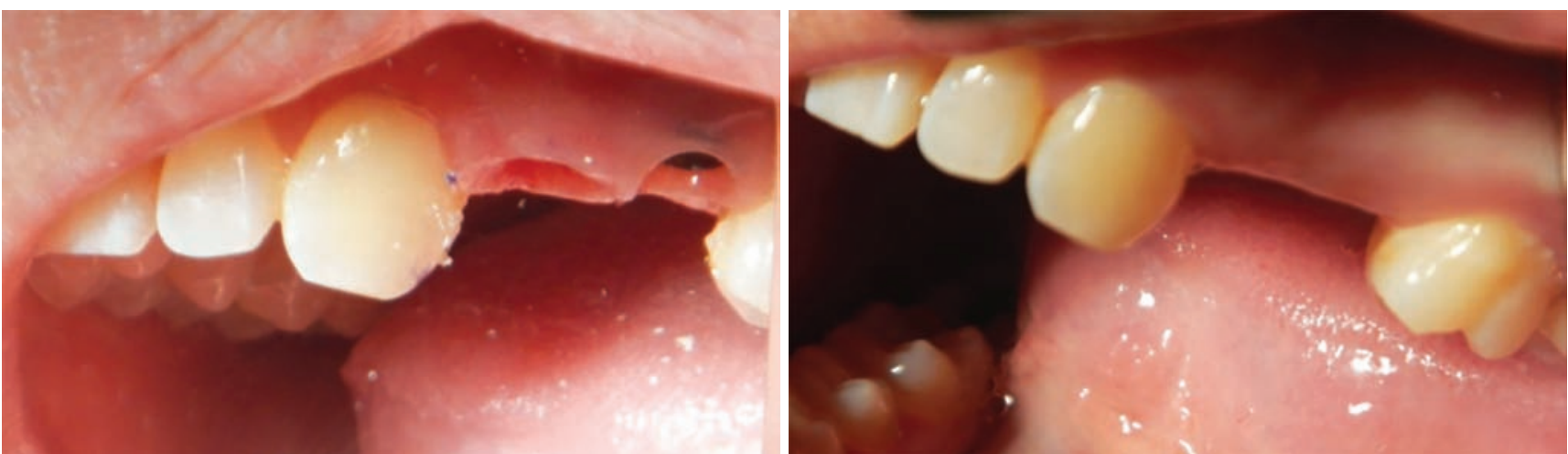

Fig. 7: Buccal views show the end result of the temporary crown adaptation and gingival grow up with interdental papillae. A direct comparison can be made between the preoperative photo on the right side with complete dental papillae lose with postoperative photo and the dental papillae gain due to gradual crown modification

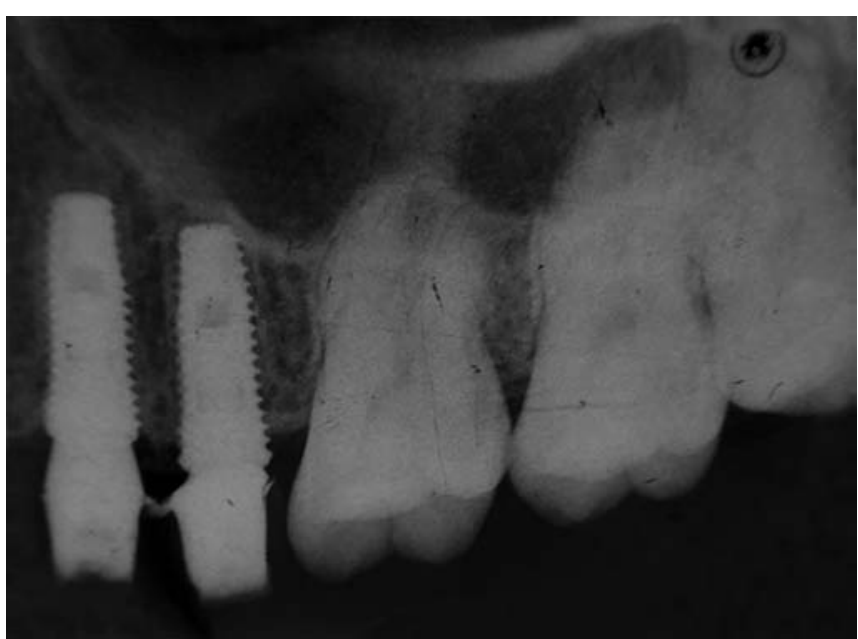

Fig. 8: Periapical radiograph after definite abutment installation. We can observe the crestal bone stability around immediate loaded implant 14

tip and prevents necrosis. ${ }^{18}$ In our case, the incision line did not include the dental papillae and was more than 1 $\mathrm{mm}$ away from the adjacent tooth (distal of the canine).

The crestal bone is another factor that influences dental papillae regeneration. Additionally, stabilization around the implant is a crucial factor for soft tissue stabilization, especially in thin biotype gingival tissue. ${ }^{19}$

Another study showed that the periodontal/periimplant biotype (phenotype) was not correlated with either the presence or absence of papilla or the shape of the dental/prosthetic crown. ${ }^{20}$ Our procedure did not involve the use of cement to issue the temporary crown; excess cement at the time of crown placement could give rise to complications, such as peri-implant inflammation, bleeding, fistulae and implant loss. ${ }^{21,22}$

Screw-retained instead of cemented provisional, restorations were used in this study which may be the reason for the lack of complications reported during the provisional stage. ${ }^{17}$

Temporizationiscrucial beforea definitecrownis placed in theestheticzone. Aswith temporary crowncustomization

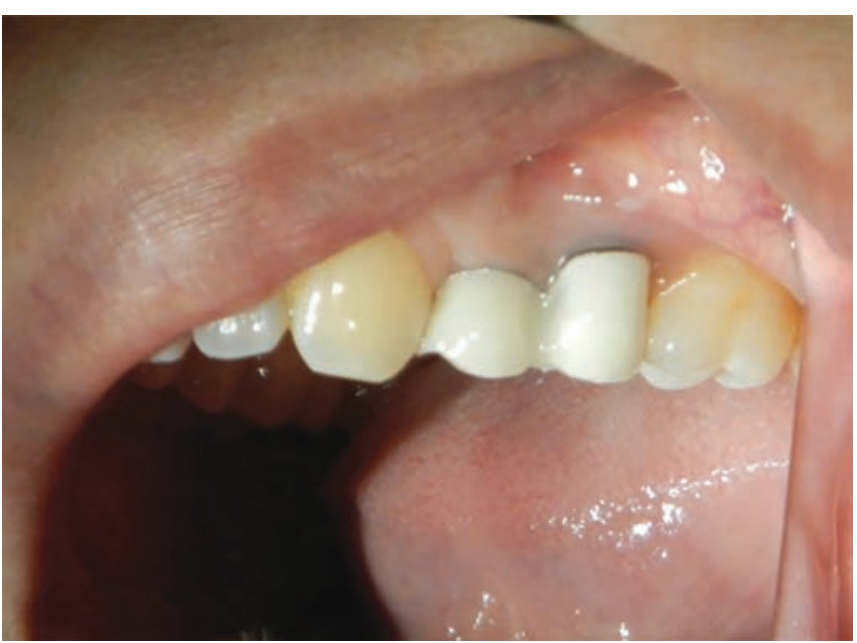

Fig. 9: Provisional crown was placed and will retain for 6 months before definite crown issued

and crown shaping, it is possible to achieve the optimum gingival contour. A smooth surface is crucial for gingival tissue growth and proliferation. The provisional crown is important for maintaining gingival esthetics, preserving the contour and volume of the gingiva, and stabilizing the gingival margin. ${ }^{23,24}$

Levin et al recommend that the provisional crown be anatomically contoured with a highly polished provisional restoration that is out of occlusal function..$^{25} \mathrm{All}$ of these factors were achieved in our case report and were retained with an abutment screw rather than with temporary cement. Another recommendation from the study by Levin et al is that temporary restoration should not be removed for a minimum of 8 weeks to protect early hard- and soft-tissue healing and to avoid compromising osseointegration..$^{25}$ This rule was broken in our study, because the temporary crown and abutment were removed on a monthly basis and there was no drawback effect on gingival growth and regeneration. With respect to adverse effects, there was gingival and papillae growth, and an increase in the height was observed month after month. 
The change in the crown emergence profiles, together with the restored contact points, contributed to soft tissue conditioning and interdental papillae growth. ${ }^{16}$ The change in the crown shape gradually offers advantages for gingival growth and adaptation. A narrow neck abutment at the first stage does not put any pressure on or push away the gingival tissue, allowing the gingival tissue to grow and thicken around the abutment. The second stage increases the diameter of the crown and creates open contact with the adjacent tooth to guide the gingival tissue and create the emergence profile. An open contact point is important at this stage to allow the interdental papillae to grow freely between the temporary crown and the adjacent tooth. Closing the interdental papillae with a prosthetic crown would inhibit the interdental papillae regeneration by providing pressure and limiting space. This new and simple method of temporization in dental implantology could save time and money in chair-side dental work.

\section{CONCLUSION}

- Composite filling material is a reliable material for crown temporization in dental implants and the papillae can grow and be shaped on the polished surface of the composite.

- Monthly abutment removal does not have any adverse effect on the papilla growth or contour.

- Inter-implant papillae can grow in the absence of the adjacent crown if this surface is polished and contoured (papillae can grow on only one surface).

\section{REFERENCES}

1. Kois JC. Predictable single tooth peri-implant esthetics: five diagnostic keys. Compend Contin Educ Dent 2001;22:199-208.

2. Chang M, Wennstrom JL, Odman P, Andersson B. Implant supported single-tooth replacements compared to contralateral natural teeth: crown and soft tissue dimensions. Clin Oral Implants Res 1999;10:185-194.

3. Lekovic V, Kenney EB, Weinlaender M, Han T, Klokkevold P, Nedic M, Orsini M. A bone regenerative approach to alveolar ridge maintenance following tooth extraction: report of 10 cases. J Periodontol 1997;68:563-570.

4. Beagle JR. Surgical reconstruction of the interdental papilla: case report. Int J Period Rest Dent 1992;12: 145-151.

5. Jemt $\mathrm{T}$. Regeneration of gingival papillae after single-implant treatment. Int J Period Rest Dent 1997;17:326-333.

6. Tarnow DP, Magner AW, Fletcher P. The effect of the distance from the contact point to the crest of bone on the presence or absence of the interproximal dental papilla. J Period 1992;63:995-996.

7. Locker ES. Patient-based outcomes of implant therapy: a review of the literature. Int J Prosthod 1998;11:453-461.

8. Jemt T. Restoring the gingival contour by means of provisional resin crowns after single-implant treatment. Int J Period Rest Dent 1999;19:20-29.
9. Belser UC, Schmid B, Higginbottom F, Buser D. Outcome analysis of implant restoration located in the anterior maxilla: a review of the recent literature. Int J Maxillofac Imp 2004;19(Suppl):30-42.

10. Palmer RM, Palmer PJ, Newton JT. Dealing with esthetic demands in the anterior maxilla. Periodontology 2000 2003;33:105-118.

11. Zetu L, Wang H-L. Management of inter-dental/interimplant papilla. J Clin Period 2005;32:831-839.

12. Nicolas elian, Tabourian G, Jalbout ZN, Classi A, Cho SC, Froum S, Tarnow DP. Accurate transfer of peri-implant soft tissue emergence profile from the provisional crown to the final prosthesis using an emergence profile. Cast J Esthet Restor Dent 2007;19:306-315.

13. Bain CA, Weisgold AS. Customized emergence profile in the implant crown-a new technique. Compend Contin Educ Dent 1997;18:41-45.

14. Hall AG, Payne AGT, Purton DG, Torr B, Duncan WJ, De Silva RK. Immediately restored, single-tapered implants in the anterior maxilla: prosthodontic and aesthetic outcomes after 1 year clinical implant. Dentistry and Related Research 2007;9:34-45.

15. Arrocha MJ, Lamas J, Arrocha MP, Garcia B. Immediate maxillary lateral incisor implants with nonocclusal loading provisional crowns. J Prosthod 2008;17:55-59.

16. Zucchelli G, Mazzotti C, Mounssif I, Marzadori M, Stefanini M. Esthetic treatment of peri-implant soft tissue defects: a case report of a modified surgical-prosthetic approach. Int J Period Rest Dent 2013;33:327-335.

17. De Rouck T, Collys K, Cosyn J. Immediate single-tooth implants in the anterior maxilla: a 1-year case cohort study on hard and soft tissue response. J Clin Periodon 2008;35: 649-657.

18. Gomez-Roman G. Influence of flap design on peri-implant interproximal crestal bone loss around single-tooth implants. Int J Oral Maxillofac Imp 2001;16:61-67.

19. Kan JY, Rungcharassaeng K, Umezu K, Kois JC. Dimensions of periimplant mucosa: an evaluation of maxillary anterior single implants in humans. J Periodon 2003;74:557-562.

20. Kawai ES, Almeida ALPF. Evaluation of the presence or absence of papilla between tooth and implant cleft palate. Craniofaci J 2008;45:399-406.

21. Pauletto N, Lahiffe BJ, Walton JN. Complications associated with excess cement around crowns on osseointegrated implants: a clinical report. Int J Oral Maxillofac Imp 1999;14: 865-868.

22. Kan JY, Rungcharassaeng K, Lozada J. Immediate placement and provisionalization of maxillary anterior single implants: 1-year prospective study. Int J Oral Maxillofac Imp 2003;18: 31-39.

23. Mijiritsky E, Mardinger O, Mazor Z, Chaushu G. Immediate provisionalization of single tooth implants in fresh-extraction sites at the maxillary esthetic zone: up to 6 years of follow-up. Implant Dent 2009;18:326-333.

24. Tortamano P, Camargo LO, Bello-Silva MS, Kanashiro LH. Immediate implant placement and restoration in the esthetic zone: a prospective study with 18 months of follow-up. Int J Oral Maxillofac Imp 2010;25:345-350.

25. Levin BP, Wilk BL. Immediate provisionalization of immediate implants in the esthetic zone: a prospective case series evaluating implant survival. Esthetics and Bone Maintenance Compend 2013;34:352-361. 